\title{
Chapter 18 \\ Consumer Evaluation of Foods from the Disaster Affected Area: Change in 3 Years
}

\author{
Hiromi Hosono, Yuko Kumagai, Mami Iwabuchi, and Tsutomu Sekizaki
}

\begin{abstract}
Since the Great East-Japan Earthquake and the following nuclear power plant accident, consumer anxiety on food and environmental contamination of radioactive substances have spread widely. This chapter examines the change in consumer attitude towards foods, focusing on beef, produced in disaster affected area based on the 6 times of web-based survey from 2011 October to 2014 March. The results showed that the risk of radioactive substances through beef consumption are not regarded as high as microbial hazards. And trust on radiation risk management implemented by government as well as food business were recovering. However, the ratio of those who stated zero WTP for foods produced in disaster affected area were rather increasing or remain constant since 2012. The results of choice experiment indicated providing information of radiation risk and risk management is effective to recover WTP for beef produced in Fukushima while knowledge level remained relatively low. We believe that continuous and accessible communication with consumers would contribute to the recovery of devastated area.
\end{abstract}

Keywords Consumer behavior - Risk perception - Trust • Knowledge • Information

\subsection{Introduction}

More than 3 years have passed since the Great East Japan Earthquake and TEPCO's first Fukushima Daiichi Nuclear Power Plant explosion that led to catastrophic damage to East Japan. The disaster caused huge damage to the social life of the Japanese, especially in eastern Japan. Immediately after the accident, consumers were concerned about radioactive substances polluting the environment and food. A

Hiromi Hosono was deceased at the time of publication.

H. Hosono • Y. Kumagai • M. Iwabuchi • T. Sekizaki

Graduate School of Agricultural and Life Sciences, The University of Tokyo, 1-1-1 Yayoi, Bunkyo-ku, Tokyo 113-8657, Japan 
considerable number of people were forced to reside in areas some distance from the affected area, and people started to pay more attention to the origin of their food to avert health risks.

The Japanese Ministry of Health, Labour and Welfare (MHLW) adopted a provisional regulation for the level of radioactive substances in foods on March 17, 2011. In April 2011, this regulation was revised upward and a maximum permissible dose of radioactive substances was set for each food category. The acceptable value for radioactive cesium in general food products was designated to be $100 \mathrm{~Bq} / \mathrm{kg}$ or less. Along with setting standards, intensive inspection of atmosphere, soil, and agricultural products was initiated to assess the contamination situation and to plan and implement decontamination activities as well as to restrain the shipping of foods contaminated with excess levels of radioactive substances. With these compositive activities, most foods that were inspected were below the regulation level of radiocesium contamination, except for wild animal or vegetables and marine products.

However, consumer anxiety about foods produced in the disaster-affected area is not expected to disappear in the short term. According to the annual consumer research implemented by the Food Safety Commission in August 2013, 29.5 and $38.0 \%$ of responders felt very uneasy and uneasy, respectively, about the risk of radioactive substances in foods. The ratio of feeling uneasy ranked the second highest after microbial contamination (20.7 and $60.1 \%$ ) among 12 food-related hazards, but when the focus was on those who felt very uneasy, radioactive substances ranked the highest. Compared with the survey in 2011 and 2012, the ratio of those who felt very uneasy and uneasy about food contamination with radioactive substances was decreasing; 88.5, 80.3, and 74.2 \% in August 2011, March 2012, and September 2012, respectively, although considerable numbers of people were still anxious about the risk.

Other consumer research also indicated that there was broad consumer anxiety about radiation risk (Kito 2012; Hangui 2013; Kurihara et al. 2013). Ujiie (2012, 2013) conducted research every 3 months about consumer acceptance of foods produced in Fukushima and Ibaraki prefectures between March 2011 and February 2013. The price differences in produce between these two sites and another area have been regarded as a willingness to accept (WTA) the situation. In Ujiie's analysis, WTA's were separated into "health risk estimation due to radioactive contamination" and "effect of production at the site." As a result, WTA increased in August 2011, which may have been due to a high dose of radiocesium detected in beef. Yoshida (2013) conducted two consumer surveys (January and December 2012) and warned of the possibility of a regime shift regarding foods from the disaster-affected area; the shift can occur in people experiencing catastrophic shock beyond resilience. Research by other consumers also noted the high anxiety, highrisk perception, and difficulty of recovering consumer confidence.

In this article, we describe the change in Japanese consumer attitudes, knowledge, risk perception, and food-purchasing behavior based on a series of web-based consumer surveys implemented from 2011 to 2014. 


\subsection{Research Outline}

We conducted consecutive web-based consumer surveys from October to November 2011 ( $\mathrm{N}=4363)$, March 2012 ( $\mathrm{N}=5028)$, January 2013 ( $\mathrm{N}=6357)$, and February $2014(\mathrm{~N}=9678)$ to investigate consumer attitudes and knowledge on radioactive substances, risk perception, and risk management measures taken in Japan with a focus on beef. The first two surveys were monitored by Nikkei Research Inc. and the others were monitored by Nippon Research Center, Ltd. The respondents included both males and females recruited from all prefectures aged in their 20s-60s. After the 3rd and the 5th (last) surveys shown above, a web-based donating experiment was offered to the 1881 (4th) and 1822 (6th) participants, respectively, selected from the 3rd and 5th survey responses. In this experiment, the participants received 100-10,000 JPY as the result of the Ultimatum Game. Using this money, they were then asked whether to donate or not. Ten charity organizations were provided as options, including enhancement of food radiocesium monitoring, compensation for farmers, subsidization for recovery from the tsunami-affected area, research on radiation risk, and development of new energy resources.

The 1st to 3rd and 5th surveys covered the following subjects: (1) perceived risk level of eight (or seven) beef-related hazards; (2) knowledge about food safety risks and risk management focusing on radiocesium; (3) attitude toward food safety and radiation risk management; (4) intention to support rehabilitation and reconstruction from the disaster; (5) intention to purchase food produced in East Japan and Fukushima prefecture; and (6) demographic characteristics such as age, gender, residential area, and household members. We also implemented the beef choice experiment on the 3rd and 5th survey and risk management measure choice experiment on the 4th and 6th survey. Before the beef choice experiment, some respondents were provided with information about radiation risk and the risk management measures conducted after the disaster. The information included risk of radioactive cesium from foods, standards and risk reduction measures taken in Japan, and the results of food radiation inspections. The demographic characteristics of the respondents are shown in Table 18.1. In the following section, we mainly focus on the 3 rd and 5 th surveys and the subsequent donating experiment.

\subsection{Results}

\subsubsection{Risk Perception}

Eight hazards were itemized regarding assumed degrees of health risk originating in beef: enterohemorrhagic Escherichia coli, Salmonella sp., Campylobacter spp., antibiotic residues, radioactive substances, bovine spongiform encephalopathy, allergies, and cloned beef. Respondents were asked to rate them on a scale from 


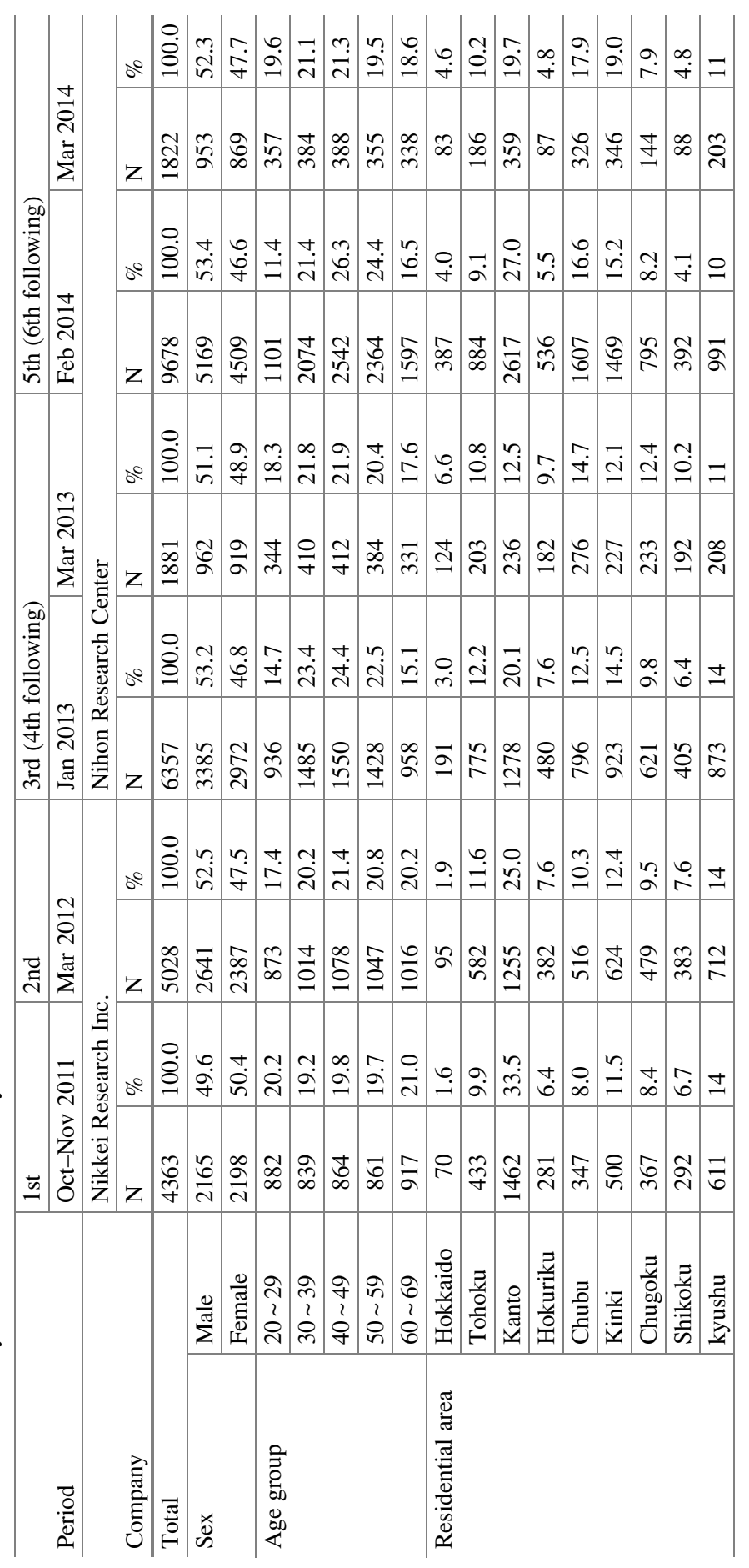




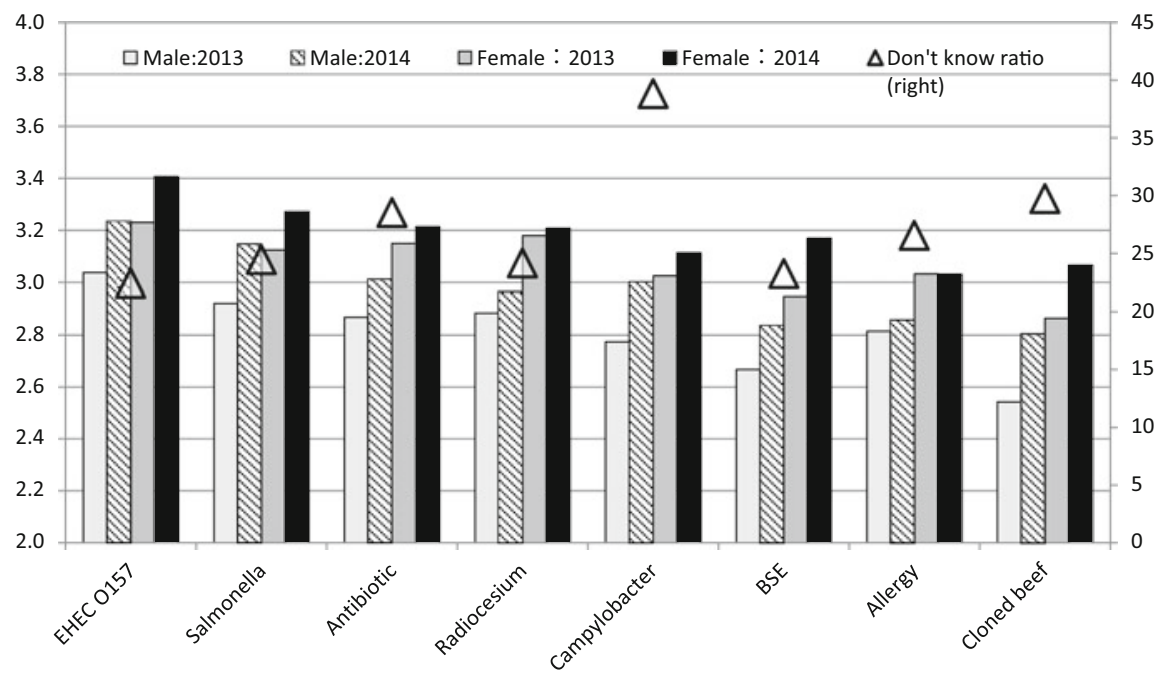

Fig. 18.1 Risk perception and the rate of choosing the "don't know" option. Left axis shows the average of responses from no risk (0) to high risk (5) and right axis shows the percentage of responses choosing "don't know" option

no risk (0) to very high risk (5). Considering cases having no idea about hazards or no ability to assume risk, the option of "have no idea" was included. Average perceived risk levels by gender for the 3rd and 5th surveys are shown in Fig. 18.1.

Compared to the 3rd survey, the 5th survey showed a general tendency for higher risk perception. Women were more apt to assume higher risk in all hazards than men. For individual hazards, enterohemorrhagic E. coli was ranked highest in every survey and for both genders. Approximately $25 \%$ of respondents chose "Don't know" to each hazard, with around $40 \%$ in the case of Campylobacter. Radiocesium was ranked 3rd highest among women while 5th highest among men.

To investigate the perceived risk level of Japanese beef compared to imported beef, in the 6th survey we asked the risk level of three hazards from eating beef distributed in US, France, and China: enterohemorrhagic E. coli, bovine spongiform encephalopathy, and radiocesium. Half of the respondents were asked to answer the Japanese beef risk level at first and the others were asked Japanese beef risk level at the end while the other country of origin was randomly presented. Figure 18.2 shows the results from these questions. The perceived risk level of acquiring enterohemorrhagic $E$. coli or bovine spongiform encephalopathy by eating Japanese beef were lower than the other countries, whereas radiocesium was similar to USA and France and lower compared to Chinese beef. In the cases where Japanese beef was presented at the end, the perceived risk level was lower than when it was presented first. 


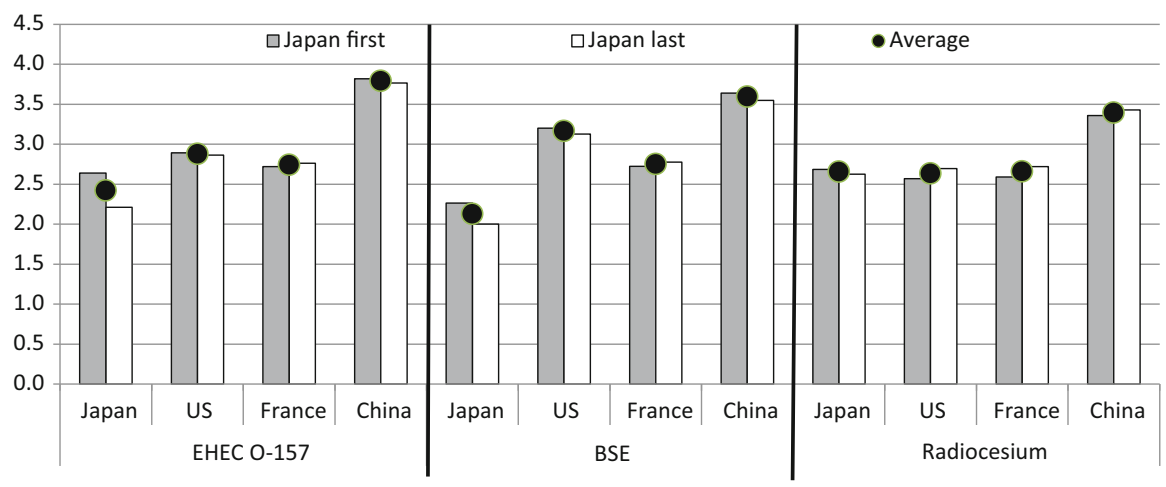

Fig. 18.2 Comparative risk perception of beef distributed in Japan, USA, France, and China. This figure shows the average of responses from no risk (0) to high risk (5)

\subsubsection{Attitude and Willingness to Pay for Foods from the Disaster-Affected Area}

Attitudes toward foods produced around the disaster-affected area were asked in the 2nd, 3rd, and 5th surveys. We provided several statements and the respondents were asked to answer to what extent they agreed with the statements; 4 and 6 Likertscales were used in the 3rd and 5th surveys, respectively. The ratios of those who agreed to each statement are shown in Fig. 18.3. The results showed that approximately half of the respondents somewhat agreed to the purchase of foods away from the devastated area after the nuclear power plant explosion. Approximately $45 \%$ of respondents thought agricultural produce from Fukushima should not be used for a school lunch. These ratios slightly increased over the last 3 years. In contrast, approximately $50 \%$ were willing to purchase food from the Kanto/ Tohoku region as well as Fukushima prefecture to support the recovery and the ratio was increasing. Approximately $75 \%$ of responders considered that they can contribute to the recovery by purchasing food from the devastated area.

Willingness to pay for foods produced around the radiation-affected area is shown in Fig. 18.4. Respondents were asked to choose the highest price they would pay for an item of food if radiocesium was not detected or was below the regulation level from $0 \%$ (do not want to buy) to $200 \%$ (twice as much as normal prices) in $10 \%$ increments. In all surveys, approximately $70 \%$ of the responders did not want to pay the normal price if radiocesium was below the regulation level. In addition, the ratio of those who did not want to buy $(0 \%)$ increased between the 2nd and 3rd surveys from around 10 to over $20 \%$. Similarly, even if radiocesium was undetected in the produce, around $15 \%$ of responders answered that they did not want to buy it in the 3rd and 5th survey, which was an increase of more than $5 \%$ from the 1st and 2nd surveys. Therefore, although the radiocesium regulation levels in general foods was strengthened in April 2012 from 500 to $100 \mathrm{~Bq} / \mathrm{kg}$, the survey results indicate that this revision did not increase consumer confidence about the safety of foods produced around the devastated area. 


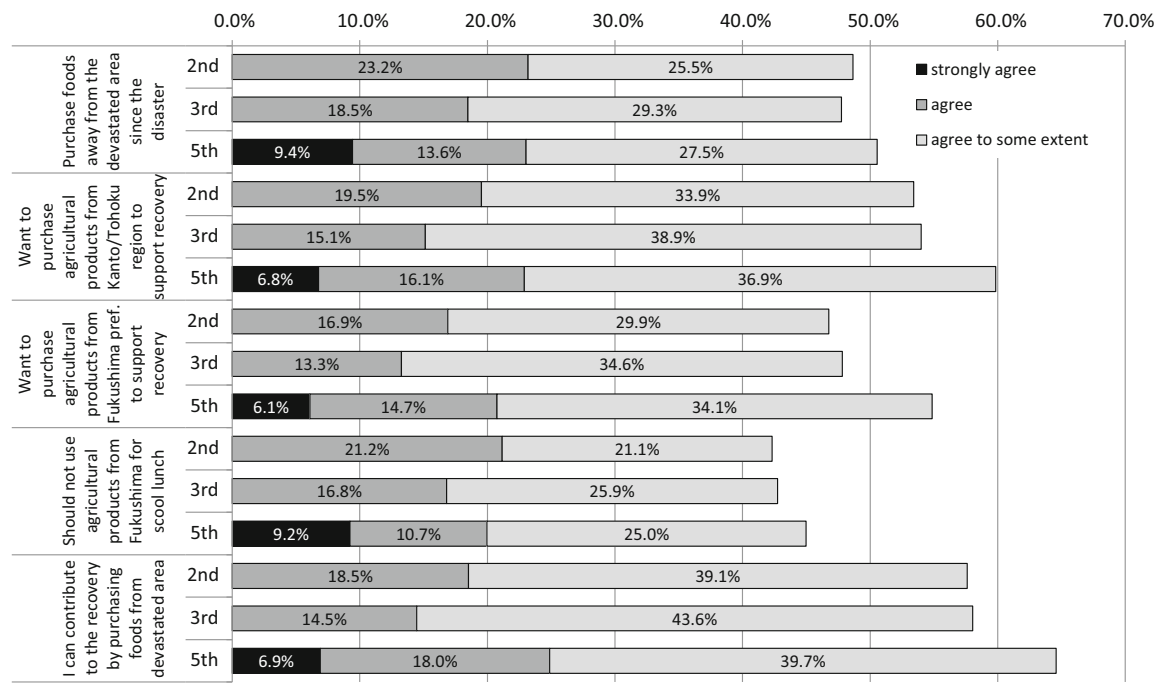

Fig. 18.3 The ratio of those who agree to each statement

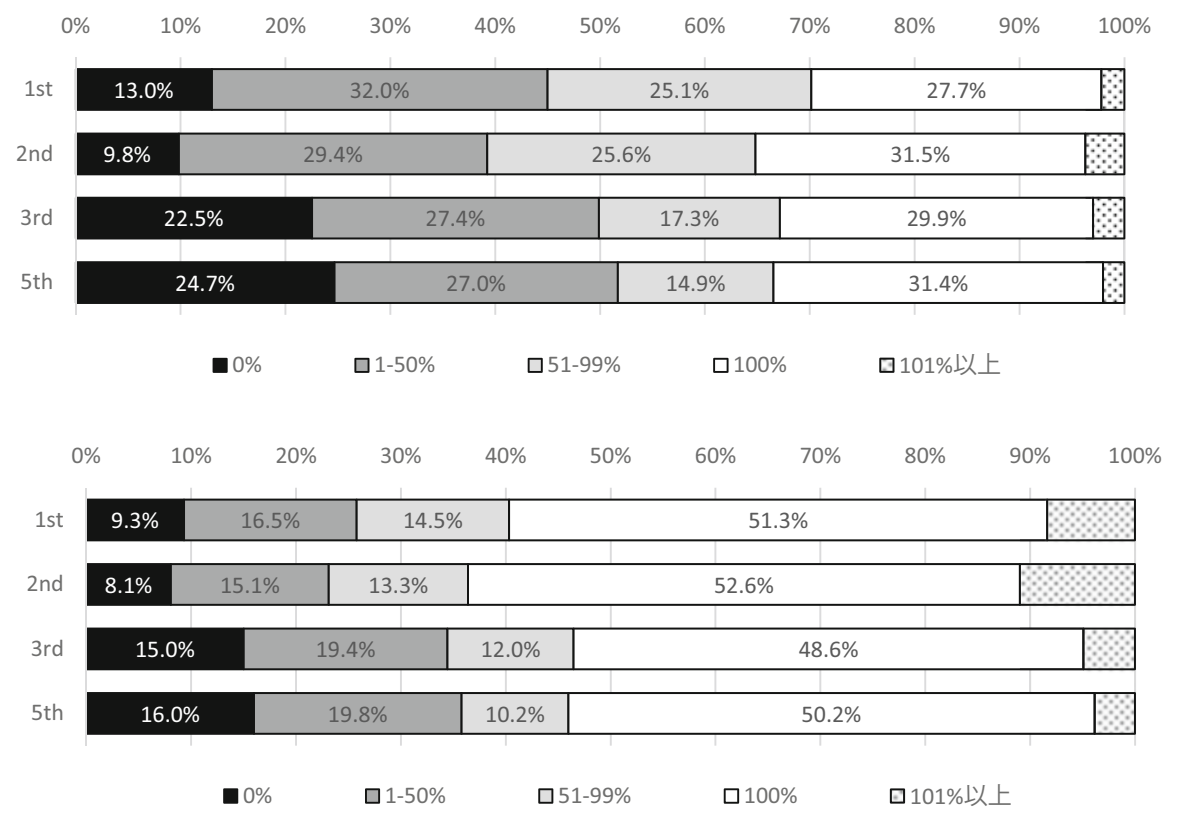

Fig. 18.4 WTP for foods produced in the disaster affected area. Radiocesium at below the regulation level (upper results) and not detected (lower results) 


\subsubsection{Trust About Risk Management of Radioactive Substances in Foods}

Consumer trust about the efforts made by stakeholders to manage radiation risk in foods was queried in the 2nd, 3rd, and 5th surveys (Fig. 18.5). The choices ranged from (strongly) agree to (strongly) disagree using the 4 or 6 Likert-scale, which is similar to that used for the attitude questions. In the 2nd survey, slightly less than $20 \%$ of the respondents agreed to the questions "The central government provides necessary information for citizens enabling them to judge the safety of food regarding radioactive substances" and "I can trust on the radiation risk management taken by the central government." The affirmative answer to trust about risk management measures taken by local government, food companies, and retailers ranked higher than risk management measures taken by the central government in the 2nd survey. The percentage of "agree" and "somewhat agree" regarding trust about radiation risk management of central or local government as well as other stakeholders in the food chain increased in the 3rd and 5th surveys. However, the results showed that more than half of the respondents "(somewhat) disagree" about the trustworthiness of radiation risk management in foods 3 years after the incident. Approximately $50 \%$ of respondents answered "agree" to the question "In order to improve safety, the stricter the standard value of radioactive substances in food, the better" in the 2nd and 3rd survey and the percentage increased to over $60 \%$ in the 5 th survey. This indicates a greater consumer desire for stricter regulations about radioactive substances in foods as time passes.

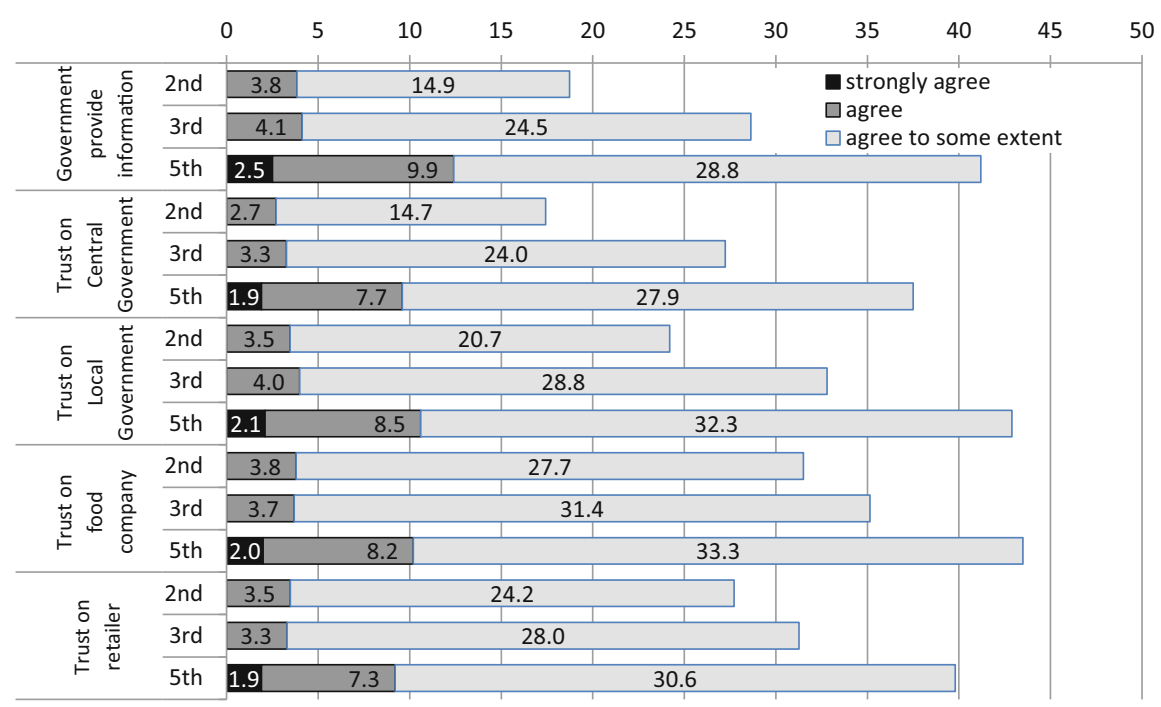

Fig. 18.5 Trust on the radiation risk management body 
Table 18.2 The correct answer rate for the questionnaire about radiation risk and risk management measures

\begin{tabular}{l|l|l|l}
\hline & 2nd (\%) & 3rd (\%) & 5th $(\%)$ \\
\hline Meaning of Becquerel and Sievert & 35.9 & 41.0 & 37.1 \\
\hline Biological half life of radiocesium & 29.2 & 33.5 & 12.3 \\
\hline Health effect of low dose exposure & 14.7 & 14.5 & 22.3 \\
\hline Permissible dose level & 15.2 & 14.5 & 11.7 \\
\hline Natural exposure dose in pease time & 27.6 & 26.7 & \\
\hline Repair function of gene & 27.7 & 23.8 & \\
\hline Once shipment ban applied, it take 1 month before reshipping & 11.0 & 11.8 & \\
\hline Standard value of radiocesium & & 7.8 & 12.8 \\
\hline Current radiocesium exposure level in Fukushima & & & 18.9 \\
\hline Inspection result of beef & & & 19.3 \\
\hline
\end{tabular}

\subsubsection{Knowledge About Radiation Risks and Risk Management Measures}

To investigate the knowledge level of the respondents, we showed several correct/ incorrect descriptions about radiation risk and risk management measures. Respondents were asked to answer if the description is "true," "not true," or "I don't know". The presented descriptions were not the same between the surveys due to the changing conditions and provided information. Table 18.2 shows the correct answer rate before information was provided. The result showed that approximately $40 \%$ of respondents understood the meaning of Becquerel and Sievert. Those who knew the difference between biological half-life and physical half-life of radiocesium was approximately $30 \%$ in the 2 nd and 3 rd survey, while it was $12.3 \%$ in the 5th survey. Natural exposure dosage in Japan and repair function of genes were queried in the 2nd and 3rd surveys and approximately $25 \%$ of people were aware of them. Knowledge of the permissible dose from foods ( $1 \mathrm{mSv}$ ), standard value of radiocesium in general foods $(100 \mathrm{~Bq} / \mathrm{kg})$ and current radiocesium exposure levels in Fukushima were lower, less than $20 \%$ in the 5 th survey.

\subsubsection{Satisfaction Levels for Radioactive Substance Management in Food}

We asked about satisfaction with radioactive substance management in food by the government in the 3rd and 5th surveys. Satisfaction levels by gender and age group are shown in Fig. 18.6. The percentage of respondents who answered "not satisfied" was 19.3 and $29.3 \%$ in the 3rd and 5th surveys respectively, with a tendency to increase with age. Although trust levels increased as time passed, satisfaction 


\begin{tabular}{|c|c|c|c|c|c|c|c|c|c|}
\hline & $\square$ Never thought & not satisfied & \multicolumn{3}{|c|}{$\square$ rather not satisfied } & \multicolumn{2}{|c|}{$\square$ rather satisfied } & \multicolumn{2}{|c|}{$\square$ satisfied } \\
\hline & $10 \%$ & $20 \%$ & $40 \%$ & $50 \%$ & $60 \%$ & $70 \%$ & $80 \%$ & $90 \%$ & $100 \%$ \\
\hline male & $10.0 \%$ & $29.9 \%$ & & & $.7 \%$ & & & $2.2 \%$ & $2.3 \%$ \\
\hline female & $13.3 \%$ & $28.7 \%$ & & & $36.8 \%$ & & & $19.6 \%$ & $1.5 \%$ \\
\hline $20 \mathrm{~s}$ & $18.3 \%$ & $19.1 \%$ & & & & & & & $4.1 \%$ \\
\hline $30 \mathrm{~s}$ & $15.5 \%$ & $23.6 \%$ & & & $.5 \%$ & & & $1.9 \%$ & $2.6 \%$ \\
\hline & & & & & & 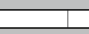 & & & \\
\hline $40 \mathrm{~s}$ & $11.3 \%$ & $30.9 \%$ & & & $36.2 \%$ & & & $20.3 \%$ & $1.4 \%$ \\
\hline $50 \mathrm{~s}$ & $9.1 \%$ & $32.6 \%$ & & & $37.4 \%$ & & & $192 \%$ & $17 \%$ \\
\hline & & & & & & 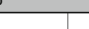 & & & \\
\hline $60 \mathrm{~s}$ & $5.6 \%$ & $36.5 \%$ & & & $34.9 \%$ & & & $22.1 \%$ & $0.9 \%$ \\
\hline
\end{tabular}

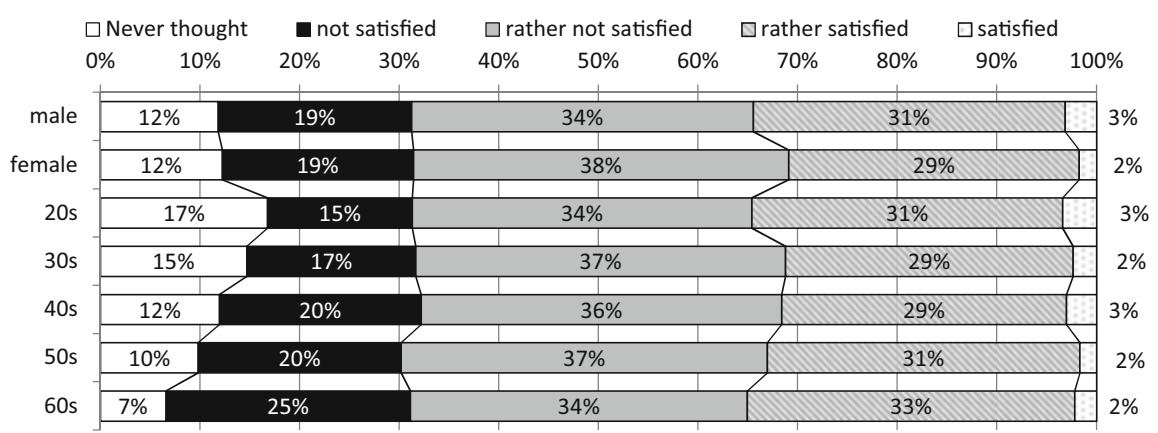

Fig. 18.6 Satisfaction level of radiation risk management in the 3rd (upper results) and 5th (lower results) surveys

decreased. Only a few percentage of respondents answered "satisfied." The younger respondents were more likely to respond "have never thought about it."

The relationship between satisfaction levels for radioactive substance management in food and WTP for food from disaster-affected areas is shown in Fig. 18.7. In the 3rd survey, as satisfaction levels rose, willingness to pay for foods from the devastated area increased. The gap between "below regulation level" and "not detected" became smaller as the satisfaction level increased. However, the average WTP among those satisfied with the management was not highest in the 5th survey. The relationship between knowledge and risk perception was inexplicable in the 5th survey (Fig. 18.8). Higher knowledge and lower risk perception related to satisfaction in the 3rd survey; however, the correct answer rate of "satisfied" people was higher, but perceived risk level was not lowest in the 5th survey. Further research to investigate the constituent of satisfaction is expected.

\subsubsection{Results of the Beef Choice Experiment}

Table 18.3 shows the estimated parameters applied to the multinomial logit model of a beef choice experiment. Before the experiment, we provided a 3-min movie 

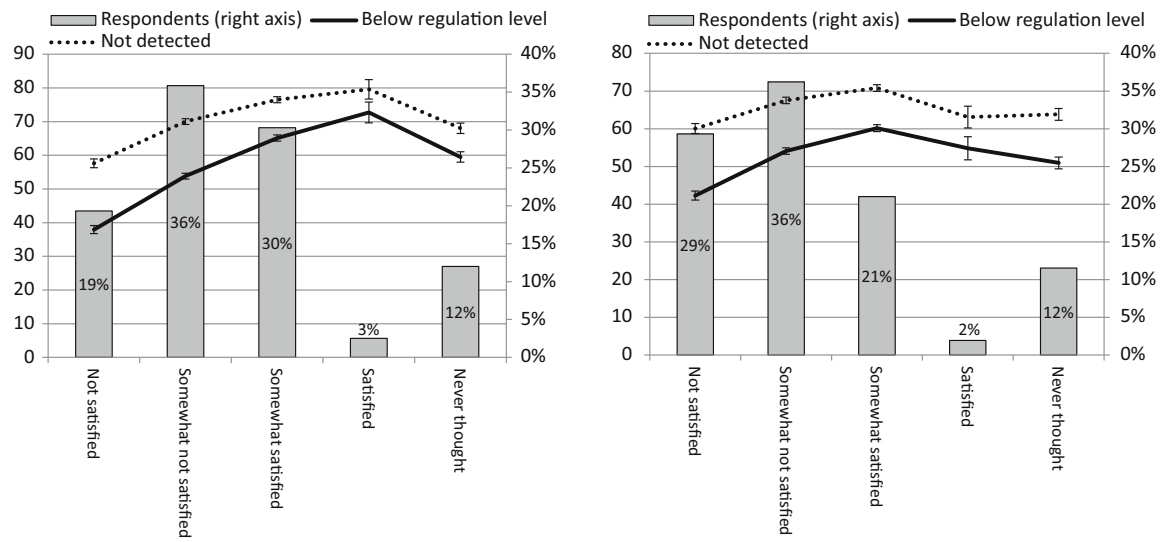

Fig. 18.7 Relationship between satisfaction level and WTP for foods from the devastated area
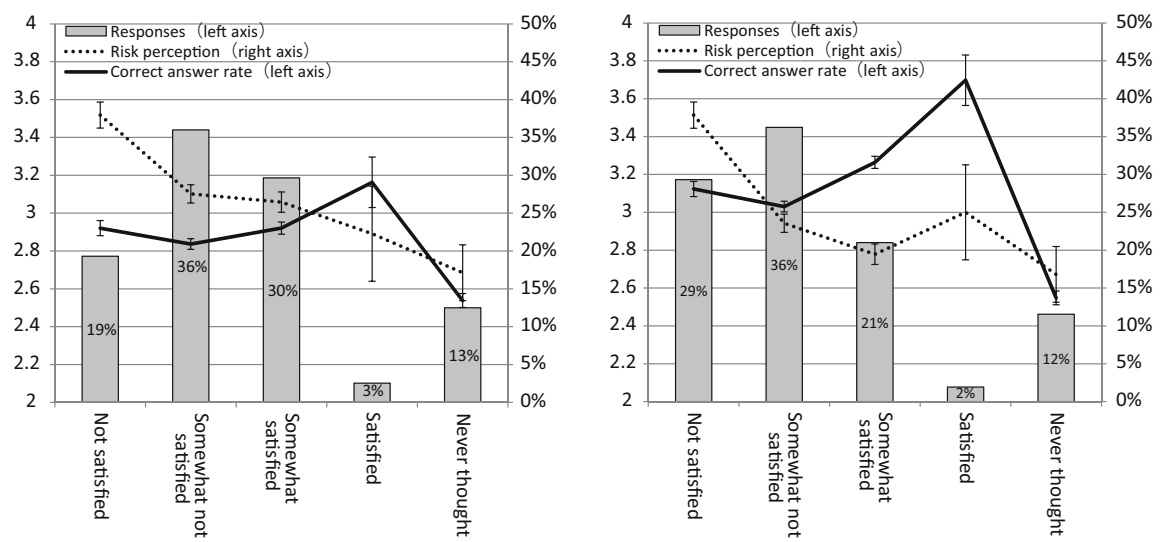

Fig. 18.8 Relationship between satisfaction level, risk perception, and correct answer rate

explaining the risk and risk management of radioactive substances in foods. However, $33.4 \%$ of those who were supposed to be provided with information stopped watching without waiting for the end. Therefore, only approximately $30 \%$ of respondents were provided with information. The attributes for beef were origin of beef (four domestic sites in Japan, USA and Australia), price (from 78 JPY to 468 JPY per $100 \mathrm{~g}$ ) and inspection results of radioactive substances. Inspection results were shown in "Becquerel/kg in number" (less than $10 \mathrm{~Bq} / \mathrm{kg}$, less than $25 \mathrm{~Bq} / \mathrm{kg}$, less than $50 \mathrm{~Bq} / \mathrm{kg}$ or less than $100 \mathrm{~Bq} / \mathrm{kg}$ ) or "Words" at a similar level as a number (not detected, less than 1/4 of regulation level, less than $1 / 2$ of regulation level or below regulation level). Respondents were asked to answer nine times for choice experiments for which the same alternatives were presented in the 4 th or 5 th choice and 9 th choice. Only those who chose the same alternative 
Table 18.3 The estimated parameters applied to the multinominal logit model

\begin{tabular}{|c|c|c|c|c|c|}
\hline & & \multicolumn{2}{|l|}{ Model 1} & \multicolumn{2}{|l|}{ Model 2} \\
\hline & & Coefficients & P value & Coefficients & P value \\
\hline \multirow[t]{9}{*}{ attribute } & Constant : Domestic & $0.253 * * *$ & 0.00 & $0.280 * * *$ & 0.00 \\
\hline & Constant : Import & 0.280 *** & 0.00 & $0.253 * * *$ & 0.00 \\
\hline & Price & -0.005 & 0.47 & -0.005 & 0.46 \\
\hline & Production site : Hokkaido & 0.032 & 0.22 & 0.032 & 0.22 \\
\hline & Production site : Fukushima & -0.029 & 0.13 & $-0.081^{*}$ & 0.10 \\
\hline & Production site : Kagoshima & -0.001 & 0.98 & 0.000 & 0.99 \\
\hline & Production site : US & -0.029 & 0.28 & -0.028 & 0.29 \\
\hline & Contamination level: in $\mathrm{Bq} / \mathrm{kg}$ & 0.002 & 0.94 & 0.003 & 0.94 \\
\hline & Contamination level: in words & 0.028 & 0.38 & 0.028 & 0.37 \\
\hline \multirow{7}{*}{$\begin{array}{l}\text { Cross } \\
\text { term }\end{array}$} & Fukushima* Complete info. & $0.102 *$ & 0.06 & $0.095^{*}$ & 0.08 \\
\hline & $\begin{array}{l}\text { Fukushima* previous } \\
\text { knowledge }\end{array}$ & & & $0.218 * *$ & 0.02 \\
\hline & Fukushima* risk perception & & & $-0.061 * * *$ & 0.00 \\
\hline & Fukushima* risk can't judge & & & $-0.173 * *$ & 0.02 \\
\hline & Fukushima* satisfaction level & & & $0.096^{* * *}$ & 0.00 \\
\hline & No. of observation & 29,832 & & 29,832 & \\
\hline & $\mathrm{AIC} / \mathrm{N}$ & 2.762 & & 2.761 & \\
\hline
\end{tabular}

$*(\mathrm{p}<0.1), * *(\mathrm{p}<0.05), * * *(\mathrm{P}<0.01)$

in these two choice cases were applied to the analysis. Moreover, those who answered "Don't know" to some questions were excluded from the analysis. Therefore, a total of 29,832 samples were utilized for this analysis. Table 18.3 shows the estimated parameters used in the multinomial logit model.

Both models 1 and 2 show negative signs toward the production site "Fukushima" while the parameters for radiation contamination levels were not significant. This indicates the possibility that consumers focus more on the production site rather than on the result of a radiation inspection. Information was effective at increasing acceptance of beef produced in Fukushima. Also, the knowledge improved WTP for Fukushima beef. Perceived risk level also affected acceptance of Fukushima beef and those who answered "I can't judge the risk level" negatively evaluated Fukushima beef. In the previous descriptive analysis the relationship between WTP and satisfaction level were ambiguous; however, the estimated parameter of this choice experiment indicated recovered price evaluation from Fukushima labeling among those who satisfied with radiation risk management.

\subsubsection{Donating Behaviors for Devastated Area and Food Safety Risk Management}

Web-based donation experiments were implemented in the 4th $(\mathrm{N}=1881)$ and 6 th $(\mathrm{N}=1822)$ surveys. Participants were selected from the 3rd and 5th surveys, 
respectively, considering the age group, sex, residential area, and WTP. Before participating in this game, they were asked how much they would be willing to donate if they acquired 10,000 JPY in the 6th survey, which was not asked in the 4th survey. After confirming their intention to participate in the experiment, participants received 300-1300 JPY as a result of a two-player Ultimatum Game. Next, we asked their intention to draw a lottery or not using the money they received in the Ultimatum Game. If they participated in the lottery, they would get 100-10,000 JPY and if they refused to participate, they would get the money they had acquired at that stage. The average amount of money acquired at this stage was $821.0 \mathrm{JPY}$ in the 4th and 628.3 JPY in the 6th survey.

Many contributions were collected after the Great East Japan Earthquake to support affected people and recovery activities. In our research, we presented 10 activities and asked each participant to donate as much as they wanted using the money they received from the above experiment. Their donating behavior is shown in Tables 18.4 and 18.5. Women donated more than men, and the donation rate increased in the older groups. Overall donation rates increased in the 6th survey $(54.4 \%)$ compared to the 4 th survey $(46.5 \%)$. The greatest amount, approximately

Table 18.4 Donated rate by sex and age group

\begin{tabular}{l|l|l|l}
\hline \multirow{2}{*}{} & \multicolumn{2}{l}{ Donation rate } & 6th \\
\cline { 2 - 4 } & \multicolumn{2}{l}{ 4th } & Projected (\%) \\
\cline { 2 - 4 } & \multicolumn{2}{l}{ Actual (\%) } & 58.8 \\
\hline Male & 47.1 & 55.5 & 62.4 \\
\hline Female & 52.0 & 58.0 & 50.5 \\
\hline $20 \mathrm{~s}$ & 31.7 & 43.7 & 55.8 \\
\hline $30 \mathrm{~s}$ & 43.0 & 49.9 & 60.2 \\
\hline $40 \mathrm{~s}$ & 53.3 & 58.8 & 65.5 \\
\hline $50 \mathrm{~s}$ & 57.0 & 63.2 & 71.3 \\
\hline $60 \mathrm{~s}$ & 63.7 & 68.4 & \\
\hline
\end{tabular}

Table 18.5 Donated rate by activities

\begin{tabular}{l|l|l}
\hline Activities & 4th (\%) & 6th (\%) \\
\hline Recovery of Tsunami affected area & 15.1 & 15.4 \\
\hline Health monitoring for radiation exposed children & 5.4 & 7.8 \\
\hline Compensation for farmers in Fukushima & 5.1 & 4.7 \\
\hline Research on development of new energy & 4.8 & 6.4 \\
\hline Research on decontamination of radioactive substances & 4.3 & 5.4 \\
\hline Research on health effect of radiation exposure & 4.3 & 5.7 \\
\hline Compensation for farmers outside Fukushima & 2.2 & 3.0 \\
\hline Radiation monitoring of marine products & 1.9 & 2.1 \\
\hline Radiation monitoring of animal products & 1.8 & 2.4 \\
\hline Other food radiation monitoring & 1.7 & 1.8 \\
\hline Total donation & 46.5 & 54.4 \\
\hline Respondents received & 53.5 & 45.6 \\
\hline
\end{tabular}


$30 \%$ of all donations, was contributed to the recovery of tsunami-affected areas, followed by health monitoring of children from radiation exposure. In the 6th survey, more participants contributed to research such as recyclable energy, health effects of low dose exposure, and decontamination of radioactive substances. The difference in the donated amount between compensation for farmers in Fukushima and outside Fukushima decreased. Total donations for intensification of food monitoring was $5.4 \%$ (4th) and $6.2 \%$ (6th), which were the 2nd and 4th largest donations, respectively.

\subsubsection{Consumer Requirement for Food Safety Measures}

In the 6th survey, we asked the respondents to select and rank food safety measures that they considered important. We displayed 18 options randomly ordered to avoid the ordering effect; options shown at the top were usually selected more often. As a result, communicating risk with consumers about radiation risk and food poisoning were highly prioritized, whereas communicating risk about bovine spongiform encephalopathy with consumers was not highly ranked (Table 18.6). Following

Table 18.6 Consumer demand for food safety measures

\begin{tabular}{l|l|l|l|l|l}
\hline & $\begin{array}{l}1 \text { st } \\
(\%)\end{array}$ & $\begin{array}{l}2 \mathrm{nd} \\
(\%)\end{array}$ & $\begin{array}{l}3 \mathrm{rd} \\
(\%)\end{array}$ & $\begin{array}{l}4 \text { th } \\
(\%)\end{array}$ & $\begin{array}{l}5 \text { th } \\
(\%)\end{array}$ \\
\hline $\begin{array}{l}\text { Risk communication for consumers (radioactive } \\
\text { substances) }\end{array}$ & 18.1 & 7.5 & 6.0 & 4.0 & 5.1 \\
\hline $\begin{array}{l}\text { Risk communication for consumers (food } \\
\text { poisoning) }\end{array}$ & 9.8 & 14.5 & 4.7 & 4.5 & 5.7 \\
\hline Decontamination of soil & 9.8 & 5.5 & 4.9 & 7.7 & 7.1 \\
\hline $\begin{array}{l}\text { Risk communication for food industry (food } \\
\text { hygiene) }\end{array}$ & 8.7 & 7.8 & 10.6 & 4.9 & 5.1 \\
\hline Enhance radio Cs inspection (animal products) & 7.8 & 9.3 & 9.1 & 9.3 & 7.8 \\
\hline Implement BSE blanket inspection & 6.5 & 4.7 & 6.8 & 7.9 & 6.1 \\
\hline Enhance radio Cs inspection (marine products) & 6.4 & 11.7 & 9.8 & 8.9 & 5.5 \\
\hline $\begin{array}{l}\text { Research on health effect of low dose radiation } \\
\text { exposure }\end{array}$ & 4.7 & 3.9 & 3.7 & 3.1 & 7.4 \\
\hline Enhance restaurant hygiene monitoring & 4.2 & 3.7 & 4.3 & 3.4 & 5.4 \\
\hline Develop BSE vaccine & 4.2 & 2.5 & 2.8 & 2.6 & 4.5 \\
\hline Hygiene control in food distribution & 3.9 & 6.5 & 7.1 & 6.9 & 7.2 \\
\hline $\begin{array}{l}\text { Research on hestimating radiation exposure from } \\
\text { food intake }\end{array}$ & 3.3 & 3.5 & 2.4 & 3.9 & 5.2 \\
\hline Hygiene control in restaurants & 2.8 & 4.2 & 3.3 & 5.3 & 5.4 \\
\hline Enhance radio Cs monitoring (plants) & 2.3 & 3.9 & 9.8 & 8.3 & 6.3 \\
\hline Develop technology for edible raw beef & 2.2 & 1.9 & 2.7 & 3.7 & 4.0 \\
\hline Risk communication for consumers (BSE) & 2.1 & 3.3 & 4.7 & 7.2 & 3.5 \\
\hline Enhance slaughterhouse hygiene & 1.8 & 3.2 & 4.1 & 5.4 & 4.2 \\
\hline Enhance farm hygiene & 1.4 & 2.1 & 3.1 & 3.1 & 4.6 \\
\hline
\end{tabular}


these options, consumers thought that radiocesium inspection in food, especially animal and marine products should be enhanced.

\subsection{Discussion and Conclusions}

Serious efforts to reconstruct the devastated area have been undertaken since the earthquake on March 11, 2011. Regarding the radiation contamination of foods, almost all marketed foods have been shown to be below the detection limit except for some seafood, fungi, wild vegetables, and wild animals. This series of surveys indicates that consumers' perceived risk level of radioactive substances in foods is not high compared with the microbial risks. Moreover, risk from radiocesium food contamination in Japan was considered to be at a similar level to that in USA and France and lower than foods distributed in China. Meanwhile, risk of bovine spongiform encephalopathy and E. coli O157 in Japan were regarded as the lowest among the four countries. However, we could argue that consumer anxiety is not reduced if we consider the results of consumer awareness and WTP for food from the disaster-affected area.

Trust about risk management taken by stakeholders, including the government and food industry, was shown to be recovering. It seems contradictory, but consumer satisfaction did not recover like trust. Moreover, there was a correlative relationship between satisfaction level and lower risk perception as well as higher WTP for foods from the disaster-affected area in the 3rd survey; although the relationship weakened in the 5th survey. Perceived radiation risk from foods was not ranked lowest and WTP was not ranked highest among those who revealed highest satisfaction levels. Albeit further research is needed to clarify this point, one explanation is that they are satisfied with being able to choose foods that originate away from the disaster affected area by checking the production site on the label. This is partially indicated by that most people do not know about the standard value of radiocesium and/or the permissible level of exposure from foods as well as current exposure level in Fukushima. A similar result also was obtained from the beef choice experiment, where the estimated coefficient of production area as "Fukushima" was negative but the radiation contamination level (results of inspection) was not significant.

Consumers are carrying an additional burden of collecting information to understand the effects of radioactive substances on health. It is easier to feel secure by choosing foods that originate away from the disaster site rather than trying to understand risk management for radiocesium contamination and the current contamination situation. Therefore, it makes sense for consumers to avoid risk by selecting food from areas as far away from the incident site as possible.

Consumer requests for communication about radiation risk are strong as indicated in the 6th survey. To reduce the cost of collecting and processing public information, communication content and methods should be developed by involving various entities, including the food industry, experts, and consumer 


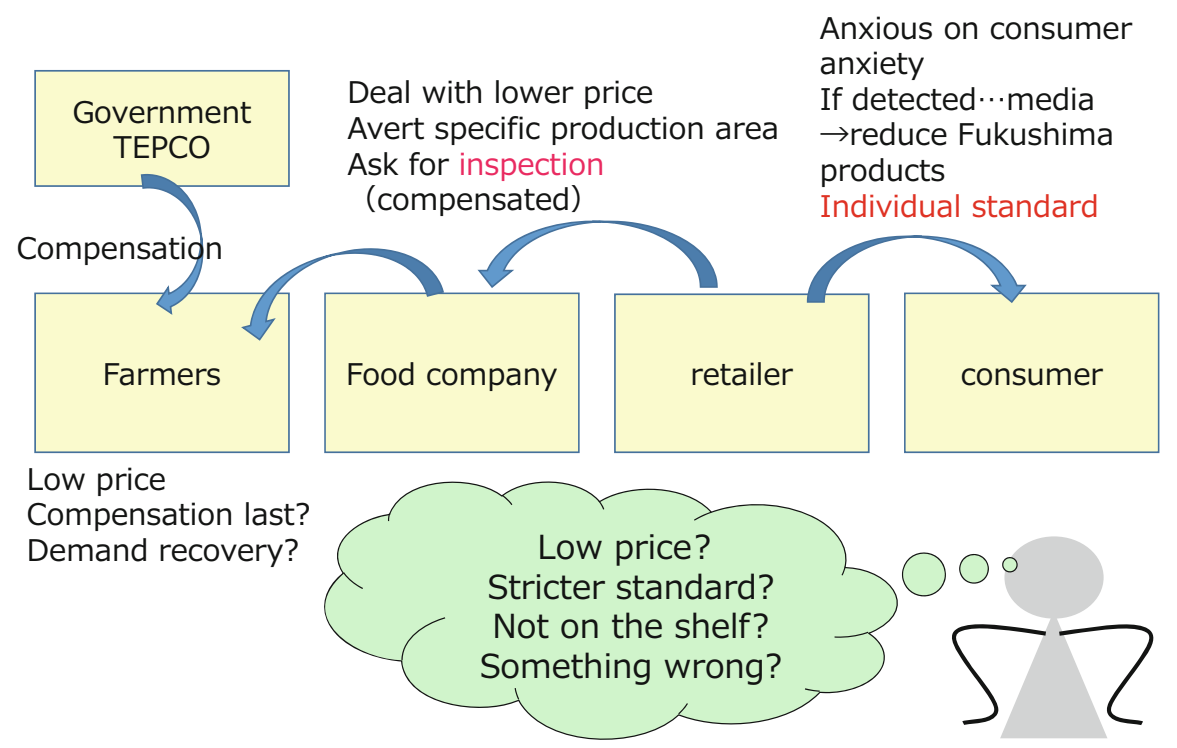

Fig. 18.9 Vicious circle on food market in devastated area

organizations. The media such as TV, newspapers, and magazines play a major role by providing information to citizens. However, less information about the situation in the devastated area is reported in the media as time passes. When radiocesium inspection results indicate values in excess of the standard value, then it is usually reported in the media, whereas a normal situation is usually not reported.

We might wait for consumers to forget about the hazard or risk, but it might take longer time. In addition, because consumer knowledge on risk and risk management measures are limited and focus more on production site rather than inspection result, it has the potential to lead consumers to regard a particular region as dangerous in the long term (Fig. 18.9), or indicates a possibility to occur regime shift as Yoshida has mentioned.

We consider that it is preferable for Japanese consumers to feel secure in the long term by acquiring knowledge about radiation risk, even it requires effort. Otherwise, they will be faced with some anxiety with every food purchase or they will be unable to enjoy the food culture or special local products produced in the affected area. Moreover, reconstruction of agricultural production in Tohoku area, which is an important food supply base for the metropolitan area, is crucial when considering the future stability of Japan's food supply. Consumer support is a vital element for promoting the reconstruction. The food risk we are facing is not only caused by radioactive substances. In order to enjoy a healthy diet and a healthy life, we should consider other food safety risks, such as the availability of food (food security), ecosystem sustainability, natural resources, and local infrastructure. 
Open Access This chapter is distributed under the terms of the Creative Commons Attribution Noncommercial License, which permits any noncommercial use, distribution, and reproduction in any medium, provided the original author(s) and source are credited.

\section{References}

Food Safety Commission of Japan (2013) Food safety monitor reports (August 2013, in Japanese) https://www.fsc.go.jp/monitor/monitor_report.html

Hangui S (2013) Consumer's response to the information provided about contamination of the food by Radioactive Materials. J Agric Rural Econ 85(3):173-180, (in Japanese)

Kito Y (2012) How do lay people perceive the health effect of radioactive substances?: an analysis of internet survey data, Y. Kito. Agric Econ 78(1) (in Japanese)

Kurihara S, Ishida T, Maruyama A, Matsuoka N, Sugawara S (2013) Construction of the system for releasing the result of radiation test and Consumer's preference analysis. J Food Syst Res 20 (3):209-214 (in Japanese)

Ujiie K (2012) Consumer's evaluation on radioactive contamination of agricultural products in Japan: decomposition of WTA into a part due to radioactive contamination and a part due to area of origin. Food Syst Res 19(2):142-155 (in Japanese)

Ujiie K (2013) Transition of consumers evaluation on radioactive contamination of agricultural products in Japan. J Rural Econ 85(3):164-172 (in Japanese)

Yoshida K (2013) An econometric analysis of consumer's averting behavior caused by the radioactive contamination of agricultural, forest and fishery products. J Rural Econ:258-265, (in Japanese) 